\title{
INFORMED CONSENT DAN REKAM MEDIS DALAM TELEMEDICINE DI INDONESIA
}

\author{
Aidha Puteri Mustikasari \\ Universitas Sebelas Maret \\ E-mail: aidhaptrm@mail.com
}

\begin{abstract}
Health services continue to develop following the updates in information technology, one of which is the use of telemedicine as a means of communicating between doctors and patients who experience long-distance consultation or treatment interactions. Not only to make it easier, but there are several new problems related to the delivery of informed consent, where any information related to disease diagnosis and treatment must be accepted, understood and approved by the patient. The recording of medical records has also experienced some turmoil because the data security system in Indonesia is not ready to allow the leakage of confidential information related to patients. Telemedicine is also not easy to do because there is no physical examination that can help doctors diagnose a disease, and it does not rule out that patients are not honest in providing information related to their condition. So this study focuses on how to deliver informed consent in the telemedicine process and the efforts that can be made to maintain the confidentiality of medical records. The government, the Indonesian Medical Association and the Medical Ethics Council are expected to support efforts to make telemedicine services in Indonesia safer and more orderly.
\end{abstract}

Keywords: Telemedicine, Informed Consent, Medical Record

\begin{abstract}
Abstrak
Layanan kesehatan terus berkembang mengikuti perkembangan teknologi informasi, salah satunya adalah penggunaan telemedicine sebagai sara berhubungan antara dokter dengan pasien yang memberi kan pengalama konsultasi atau interaksi pengobatan jarak jauh. Tidak semata-mata mempermudah namun ada beberapa hal yang menjadi masalah baru yaitu terkait dengan penyampaian informed consent yang mana setiap informasi terkain dengan diagnose penyakit dan penangana harus dapat diterima, dimengerti dan disetujui oleh pasien. Pencatatan rekam medis juga mengalami guncngan karena belum siapnya sistem pengamanan data yang ada di Indonesia memungkinkan adanya kebocoran terhadap informasi rahasia terkait dengan pasien. Telemedicine juga tidak mudah untuk dilakukan pasalnya tidak adanyanya pemeriksaan fisik yang dapat membantu dokter dalam mendiagnosa suatu penyakit, serta tidak menutup kemungkinan bahwa pasien tidak jujur dalam memberikan informasi terkait dengan keadannya. Maka penelitian ini berfokus pada bagaimana cara penyampaian informed consent dalam proses telemedicine dan upaya yang dapat dilakukan untuk menjaga kerahasiaan rekam medik. Pemerintah, Ikatan Dokter Indonesia dan Majelis Kehormatan Etik Kedokteran diharapkan dapat mendukung upaya-upaya agar layanan telemedicine di Indonesia menjadi lebih aman dan tertata.
\end{abstract}

Kata Kunci : Telemedicine, Infomerd Consent, Rekam Medik 


\section{A. Pendahuluan}

Saat ini topic kesehatan menjadi focus utama di berbagai negara di seluruh dunia. Dengan adanya wabah covid-19 banyak negara yang memfokuskan diri untuk penanganan wabah tersebut. Kesehatan merupakan unsure penting dalam kehidupan setiap manusia, baik kesehatan raga maupun jiwa. Kesehatan juga mempengaruhi setiap aktivitas dan kegiatan yang akan di lakukan. Apabila seseorang merasa dirinya tidak dalam kondisi sehat sebaiknya dilakukan penanganan karena diketahui adanya berbagai macam jenis penyakit yang dapat menyerang tubuh manusia. Penanganan terhadap suatu penyakit tersebut dapat ditempuh dalam berbagai cara seperti pengobatan, perawatan, rawat jalan, rawat inap, operasi, dan lainya. Sebelum tindakan dan/atau upaya tersbut dilakukan perlu adanya persetujuan atas tindakan yang akan di lakukan. Hal ini merupakan salah satu standar profesi sesuai dengan Pasal 51 ayat 1 Undang-undang Nomor 29 Tahun 2004 tentang Praktik Kedokteran. Standar profesi adalah pedoman yang harus digunakan dalam menjalankan profesi secara baik, dalam pelayanan medic menitikberatkan pada prosedur tindakan medik ${ }^{1}$. Salah satunya adalah mencari persetujuan atas tindakan yang akan dilakukan untuk penanganan dengan cara menginformasikan terlebih dahulu aspek-aspek yang ada dari tindakan tersebut. Hal ini di sebut Informed Consent. Berdasarkan Permenkes Nomor 290 Tahun 2008 tentang Persetujuan tindakan medik pasal 1 huruf a yang menyatakan bahwa persetujuan tindakan kedokteran adalah persetujuan yang diberikan oleh pasien atau keluarga terdekat setelah mendapat menjelasan secara lengkap mengenai tindakan kedokteran atau kedokteran gigi yang akan dilakukan terhadap pasien ${ }^{2}$. Perkembangan di bidang teknologi informasi yang berkembang cepat membuat banyaknya aktivitas dapat dilakukan melalui online termasuk dalam bdang kesehatan muncul adanya konsultasi online dengan menggunakan berbagai aplikasi yang memungkinkan hubungan jarak jauh antara dokter dengan pasien, atau sering disebut juga sebagai telemedicine. Telemedicine dapat dikatakan sebagai penggunaan teknologi informasi dan komunikasi untuk memberikan layanan medis dari jarak yang terpisah atau tidak ada tatap muka. Fasilitas komunikasi yang digunakan dapat berupa telepon, panggilan video, situs internet, atau alat komunikasi canggih lainnya ${ }^{3}$.

Dalam pelaksanaan telemedisin terdapat dua konsep yaitu real time (synchronous) dan storeand-fordward (asynchronous). Synchronous telemedicine memerlukan kehadiran kedua pihak pada saat itu karena diperlukan interaksi. Sedangkan synchronous telemedicine tidak memerlukan kehadiran kedua pihak saat itu karena dilakukan pengumpulan data medis yang selanjutnya dikirim kepada dokter untuk dievaluasi secara offline. Telemedisin yang disarankan di Indonesia berdasarkan panduan IDI tentang telemedisin dibagi menjadi lima, yaitu : ${ }^{4}$

1. Tele-expertise, yang menghubungkan dokter umum dan dokter spesialis atau antar dokter spesialis, misalnya teleradiologi.

2. Tele-consultation, yang menghubungan pasien dan dokter

1 Veronica Komalawati, Peranan Informed Consent Dalam Transaksi Teraupetik: Persetujuan dalam Hubungan dokter dengan Pasien Suatu tinjauan Yuridis. Citra Aditya Bakti. Bandung: 2002. Hal.177

Wila Chandrawila Supriadi, Persetujuan Tindakan Medik, Mandar Maju, Jakarta: 2008. Hal 1

3 Pukovisa Prawiroharjo, Peter Pratama, Nurfanida Librianty, Layanan Telemedis di Indonesia : keniscayaan, risiko., dan Batasan etika, JEKI. 2019;3(1):1-9. 27.

Pengurus Besar Ikatan Dokter Indonesia 
3. Tele-monitoring, yang digunakan tenaga kesehatan untuk memonitor berbagai parameter tubuh pasien secara virtual

4. Tele-assistance, yang digunakan untuk memberikan arahan kepada pasien, misalnya dalam proses rehabilitasi

5. Tele-robotic/tele-intervention, yaitu pengendalian jarak jauh terhadap sebuah robot dalam suatu tele-surger.

Dalam pemanfaatan telemedicine tentu menimbulkan beberapa masalah baru terkait dengan pelaksanaan ataupun regulasi yang mengaturnya, salah satunya adalah pemenuhan kewajiban tenaga kesehatan dalam suatu pelayanan medis, termasuk diantaranya penyampaian informed consent dan perlindungan data rekam medis. Maka dalam jurnal ini penulis tertarik untuk membahas persoalnya penyampaian informed consent dan perlindungan data rekam medis melalui telemedicine.

\section{B. Pembahasan}

Persetujuan yang diinformasikan secara elektronik berada di dalam proses multidekade di Amerika Serikat untuk mengubah berbagai jenis kontrak fisik dan kertas menjadi dokumen virtual yang dapat "ditandai" dan "ditandatangani" secara elektronik5. Saat ini di dunia kedokteran yang sedang menangani wabah besar covid-19 banyak sekali penanganan penyakit lain yang diubah kedalam sistem online atau yang disebut sebagai telemedicine.

Dokter perlu menyadari bahwa sistem telemedicine mempunyai keterbatasan dalam menyajikan keutuhan informasi terkait kondisi klinis seorang pasien. Dokter harus mempertimbangkan bahwa informasi yang tersaji dalam sebuah sistem telemedicine cukup untuk memunculkan keyakinan professional yang kuat sehingga dapat ditindaklanjuti menjadi penegakan diagnosis dan penentuan tatalaksana kepada pasien.

Seperti pada umumnya hubungan dokter pasien secara tradisional, hubungan dokter dan pasien yang menggunakan telemedicine juga harus memenuhi syarat yang diatur dalam Undang-undang Nomor 29 Tahun 2004 tentang Praktek Kedokteran. Pasal 39 menyebutkan bahwa praktik kedokteran dilaksanakan berdasarkan pada kesepakatan berdasarkan hubungan kepercayaan antara dokter atau dokter gigi dengan pasien dalam upaya pemeliharaan kesehatan, pencegahan penyakit, peningkatan kesehatan, pengobatan penyakit dan pemulihan kesehatan. Kesepakatan yang dimaksud adalah salah satu upaya maksimal pengabdian profesi kedokteran yang harus dilakukan dokter dan dokter gigi dalam penyembuhan dan pemulihan kesehatan pasien sesuai dengan standar pelayanan, standar profesi, standar prosedur operasional dan kebutuhan medis pasien ${ }^{6}$.

Sesungguhnya seorang dokter dapat menegakkan 2 dari 3 diagnosis hanya berdasarkan kemampuan anamnesis yang baik, namun pemeriksaan fisik akan memberikan $20 \%$ informasi tambahan yang mungkin signifikan dan bahkan mengubah arah diagnosis ${ }^{7}$. Pemeriksaan fisik masih mungkin dilakukan dengan telemedicine menggunakan video

5 John T. Wilbanks. "Electronic Informed Consent in Mobile Application Research. The Journal of Law, Medicine \& Ethics. 48 S1 (2020)

6 Arman Anwar. Aspek Hukum Penggunaan Telemedicine. Forum Informatika Kesehatan Indonesia No.1 (2013)

7 Walker HK, Hall WD, Hurst JW, editors. Clinical methods: The history, physical, and laboratory examinations. 3rd ed. Boston: Butterworths; 1990 
call namun yang non-observasional (palpasi, perkusi, dan auskultasi) atau memerlukan manuver khusus tidak mungkin didapatkan melalui wahana telemedicine ${ }^{8}$.

Pada pasal 4 Permenkes Nomor 20 tahun 2019 disebutkan bahwa pelayanan telemedicine harus dilakukan sesuai dengan standar yang ada di dalam Permenkes Nomor 1438 tahun 2010 tentang Standar Pelayanan Kedokteran pada pasal 10 menyebutkan bahwa Panduan Praktik Klinik harus memuat hal salah satunya adalah pemeriksaan fisik. Demikian juga di dalam Buku Penyelenggaraan Praktik Kedokteran yang Baik di Indonesia yang dikeluarkan oleh Konsil Kedokteran Indonesia tahun 2006, bahwa dokter harus melakukan pemeriksaan fisik dan mental pasien ${ }^{9}$.

Tidak dapat dipungkiri adanya keterbatasan terhadap informasi yang disampaikan menyebabkan sistem pelayanan telemedicine memiliki resiko yang besar dalam menentukan langkah perawatan. Termasuk dalam penyampaian informed consent. Dalam hal ini dokter tidak dapat melakukan tindakan langsung kepada pasien maka infomasi yang dapat di berikan antara lain termasuk:

1. Diagnosis

2. Penanganan yang dapat di lakukan oleh pasien pribadi

3. Obat dan efek samping

4. Langkah atau pengobatan selanjutnya yang harus di lakukan pasien.

Dalam hal ini penjelasan harus diberikan secara detail dan jelas agar tidak terjadi kesalahpahaman antara dokter dengan pasien.

Dokter yang berkiprah dalam dunia telemedis harus sangat berhati-hati dalam memberikan saran medisnya sebagaimana dalam praktik dunia nyata. Jangan sampai saran ini bersifat keliru (hoax), mengiklankan produk tertentu, atau bahkan mengiklankan dirinya sendiri secara berlebihan ${ }^{10}$. Dokter tersebut juga harus memperhatikan kemungkinan bahwa sarannya tersebut digunakan pembaca untuk mendiagnosis dirinya sendiri, atau bahkan dijadikan "senjata" bagi pasien tertentu untuk menyerang sejawat lainnya seperti halnya dalam cybermedicine ${ }^{l 1}$.

Aturan yang belum terbarukan terkait rekam medis tentunya juga akan bersinggungan dengan informed consent yang seharusnya diberikan kepada pasien setelah menerima penjelasan dokter dan bersedia untuk mendapatkan terapi dari dokter. Meskipun dengan telemedicine dokter tidak melakukan suatu tindakan terhadap pasien, namun pemberian rekomendasi obat sebagai yang dapat menimbulkan risiko bagi pasien misalnya reaksi alergi. Maka sebaiknya pada obat-obat yang ada kemungkinan menimbulkan efek samping pada pasien tetap dilakukan informed consent secara tertulis.

8 Pukovisa Prawiroharjo, Peter, Pratama, Nurddanida Librianti. Layanan Telemedis di Indonesia: Keniscayaan, Risiko, dan Batasan Etika. Jurnal Etika Kedokteran Indonesia.Vol. 3 No.1 (2019). hlm: 1-9

9 Konsil Kedokteran Indonesia, Penyelengaraan Praktik Kedokteran yang Baik di Indonesia, 2006, h.8

10 Prawiroharjo P, Meilia PDI. Dokter beriklan: Sebuah tinjauan menurut Kode Etik Kedokteran Indonesia (KODEKI) tahun 2012. J Etik Ked Ind. 2017 Oct 11;1(1):13. https://doi.org/10.26880/jeki.v1i1.4.

11 Santosa F, Purwadianto A, Sidipratomo P, Pratama P, Prawiroharjo P. Sikap etis dokter terhadap pasien yang "mendiagnosis" diri sendiri menggunakan informasi Internet pada era cyber medicine. J Etik Ked Ind. 2018 Jun 12;2(2):53. https://doi. org/10.26880/ jeki.v2i2.16. 
Seorang dokter yang menggunakan telemedicine sebagai sara dalam pengobatan juga harus memperhatikan rekam medis pasien yang ditangani, melihat banyak sekali tindak kejahatan cyber. Setiap penyedia layanan internet dan penyedia layanan server seharusnya berjanji akan menjaga kerahasiaan dan tidak akan menyadap data yang digunakan kliennya. Apalagi, mengingat data yang mereka layani berukuran sangat besar, dan juga merupakan suatu data yang harus dijaga kerahaisannya. Perlindungan data melalui metode enkripsi sangat penting untuk menjaga segala informasi yang ada dalam proses telemedicine. Selain itu, hal ini mudah dicegah dengan menggunakan penyedia layanan internet dan penyedia layanan server yang telah dikenal memiliki reputasi yang baik; mereka akan berusaha sepenuhnya untuk menjaga kerahasiaan ini karena pelanggaran dapat berakibat tuntutan hukum dan hilangnya kepercayaan public baik terhadap dokter, tenaga kesehatan ataupun platform yang digunakan untuk media konsultasi. Masalah data pasien ini harus pikirkan secara matang agar semua pihak di dalam proses telemedicine terlindungi setiap datadatanya. Data di Amerika Serikat mencatat 1.138 kasus penerobosan data dalam tahun 2009-2017 yang melibatkan 164 juta pasien, dengan rincian 22,2 juta pasien merupakan akibat kasus pencurian perangkat, 20,3 juta pasien akibat akses ilegal, 133,8 juta pasien akibat peretasan, 5,7 juta pasien akibat data hilang, dan 700 ribu pasien akibat pembuangan data yang tidak tepat. Padahal, Amerika Serikat mempunyai Health Insurance Portability and Accountability Act (HIPAA) yang dicetuskan oleh Departemen Kesehatan dan Layanan Masyarakat Amerika Serikat untuk meregulasi keamanan data kesehatan rakyatnya ${ }^{12}$.

Di Indonesia sendiri pengaturan tentang telemedicine ada dalam Permenkes Nomor 20 Tahun 2019 tentang Penyelenggaraan Telemedicine Antar Fasilitas Kesehatan. Pasal 6 menyebutkan bahwa fasyankes pemberi konsultasi yang dimaksud adalah rumah sakit, sedangkan fasyankes peminta konsultasi jugalah rumah sakit, fasyankes tingkat pertama dan fasyankes lain yang dilakukan oleh dokter ber SIP yang berarti permenkes ini hanya mengatur telemedicine antar fasyankes yang tidak dapat diterapkan antara fasyankes atau doker dengan pasien ${ }^{13}$.

Maka pengaturan terkait dengan pelaksanaan Telemedicine di Indonesia harus dirincikan kembali termasuk dalam penggunaan media dan juga perlindungan data pribadi pasien.

\section{Kesimpulan}

Informed consent atau Persetujuan Tindakan Medis merupaka hal sangat penting sehingga para dokter harus selalu melaksanakan sebaik-baiknya agar tuntutan hukum dari pihak pasien dapat dihindari. Dan juga menhindari resiko medis yang akan terjadi. Dalam penggunaan sistem telemedicine dokter harus memastikan kebenaran informasi yang di sampaikan oleh pasien dan juga tetap melakukan rekam medis terhadap langkah penanganan dan saran yang diberikan kepada pasien. Prinsip dan aturan penggunaaan telemedicine dalam praktek kedokteran adalah: kemudahan akses, tanggung jawab negara, kompetensi, integritas, dan kualitas, itikad baik, keamanan dan kerahasiaan data, standarisasi, otonomi pasien dan kebebasan memilih teknologi atau netral teknologi. manfaat, keadilan, kemanusiaan, keseimbangan, perlindungan hukum.

12 Jiang J (Xuefeng), Bai G. Evaluation of causes of protected health information breaches. JAMA Intern Med. 2018 Nov 19; https://doi.org/10.1001/jamainternmed.2018.5295.

13 Carolina Kuntardjo. Dimensions of Ethics and Telemedicine in Indonesia: Enough of Permenkes Number 20 Year 2019 As a Frame of Telemedicine Practices in Indonesia. Soepra Jurnal Hukum Keshatan Vol.6 No.1 (Juni 2020) 
Dengan ini harapan kedepannya adalah adanya suatu rumpun pengaturan yang mengatur terkait dengan pemberian informed consent, perlindungan pasien dan dokter dalam sistem telemedicine serta perlindungan data terkait dengan rekam medic pasien.

\section{Daftar Pustaka}

Arman Anwar. Aspek Hukum Penggunaan Telemedicine. Forum Informatika Kesehatan Indonesia No.1 (2013)

Carolina Kuntardjo. Dimensions of Ethics and Telemedicine in Indonesia: Enough of Permenkes Number 20 Year 2019 As a Frame of Telemedicine Practices in Indonesia. Soepra Jurnal Hukum Keshatan Vol.6 No.1 (Juni 2020)

Jiang J (Xuefeng), Bai G. Evaluation of causes of protected health information breaches. JAMA Intern Med. 2018 Nov 19; https://doi.org/10.1001/jamainternmed.2018.5295.

John T. Wilbanks. "Electronic Informed Consent in Mobile Application Research. The Journal of Law, Medicine \& Ethics. 48 S1 (2020)

Prawiroharjo P, Meilia PDI. Dokter beriklan: Sebuah tinjauan menurut Kode Etik Kedokteran Indonesia (KODEKI) tahun 2012. J Etik Ked Ind. 2017 Oct 11;1(1):13. https://doi. org/10.26880/jeki.v1il.

Pukovisa Prawiroharjo, Peter Pratama, Nurfanida Librianty, Layanan Telemedis di Indonesia : keniscayaan, risiko., dan Batasan etika, JEKI. 2019;3(1):1-9. 27.

Santosa F, Purwadianto A, Sidipratomo P,

Pratama P, Prawiroharjo P. Sikap etis dokter terhadap pasien yang "mendiagnosis" diri sendiri menggunakan informasi Internet pada era cyber medicine. J Etik Ked Ind. 2018 Jun 12;2(2):53. https://doi.org/10.26880/ jeki.v2i2.16.

Veronica Komalawati, Peranan Informed Consent Dalam Transaksi Teraupetik: Persetujuan dalam Hubungan dokter dengan Pasien Suatu tinjauan Yuridis. Citra Aditya Bakti. Bandung: 2002. Hal.177

Walker HK, Hall WD, Hurst JW, editors.

Clinical methods: The history, physical, and laboratory examinations. 3rd ed. Boston: Butterworths; 1990

Wila Chandrawila Supriadi, Persetujuan Tindakan Medik, Mandar Maju, Jakarta: 2008. Hal 1

Pengurus Besar Ikatan Dokter Indonesia, Telemedicine

Konsil Kedokteran Indonesia, Penyelengaraan Praktik Kedokteran yang Baik di Indonesia, 2006, h.8 